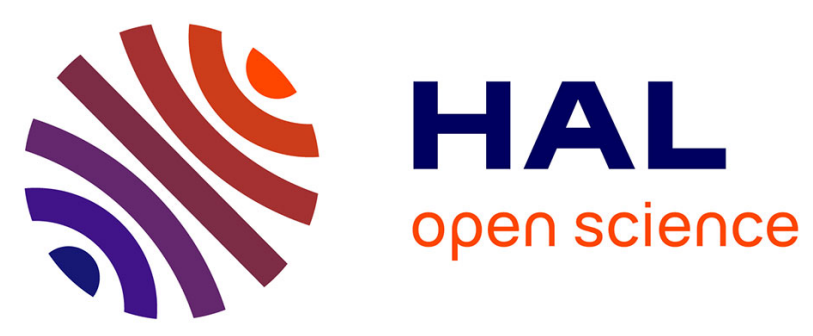

\title{
A Self-Learning Solution for Torque Ripple Reduction for Nonsinusoidal Permanent-Magnet Motor Drives Based on Artificial Neural Networks
}

Damien Flieller, Ngac Ky Nguyen, Patrice Wira, Guy Sturtzer, Djaffar Ould Abdeslam, Jean Mercklé

\section{To cite this version:}

Damien Flieller, Ngac Ky Nguyen, Patrice Wira, Guy Sturtzer, Djaffar Ould Abdeslam, et al.. A SelfLearning Solution for Torque Ripple Reduction for Nonsinusoidal Permanent-Magnet Motor Drives Based on Artificial Neural Networks. IEEE Transactions on Industrial Electronics, 2014, 61 (2), pp.655-666. 10.1109/TIE.2013.2257136 . hal-01019390

\author{
HAL Id: hal-01019390 \\ https://hal.science/hal-01019390
}

Submitted on 25 Aug 2014

HAL is a multi-disciplinary open access archive for the deposit and dissemination of scientific research documents, whether they are published or not. The documents may come from teaching and research institutions in France or abroad, or from public or private research centers.
L'archive ouverte pluridisciplinaire HAL, est destinée au dépôt et à la diffusion de documents scientifiques de niveau recherche, publiés ou non, émanant des établissements d'enseignement et de recherche français ou étrangers, des laboratoires publics ou privés. 


\title{
A Self-Learning Solution for Torque Ripple Reduction for Non-Sinusoidal Permanent Magnet Motor Drives Based on Artificial Neural Networks
}

\author{
Damien Flieller, Ngac Ky Nguyen, Member, IEEE, Patrice Wira, Member, IEEE, Guy Sturtzer, Djaffar Ould \\ Abdeslam, Member, IEEE, and Jean Mercklé
}

\begin{abstract}
This paper presents an original method, based on artificial neural networks, to reduce the torque ripple in a permanent-magnet non-sinusoidal synchronous motor. Solutions for calculating optimal currents are deduced from geometrical considerations and without a calculation step which is generally based on the Lagrange optimization. These optimal currents are obtained from two hyperplanes. The study takes into account the presence of harmonics in the back-EMF and the cogging torque. New control schemes are thus proposed to derive the optimal stator currents giving exactly the desired electromagnetic torque (or speed) and minimizing the ohmic losses. Either the torque or the speed control scheme, both integrate two neural blocks, one dedicated for optimal currents calculation and the other to ensure the generation of these currents via a voltage source inverter. Simulation and experimental results from a laboratory prototype are shown to confirm the validity of the proposed neural approach.
\end{abstract}

Index Terms-Permanent Magnet Synchronous Motor, Torque Ripple, Cogging Torque, Homopolar Current, Neuro-controller, Adaline.

\section{NOMENCLATURE}

\begin{tabular}{|c|c|}
\hline $\mathbf{i}$ & Stator current vector \\
\hline e & Back-EMF vector \\
\hline$n$ & Number of phases of PMSM \\
\hline$p$ & Number of pole pairs \\
\hline $\mathbf{K}_{1}$ & Speed normalized back-EMF vector \\
\hline $\mathbf{K}_{0}$ & $\begin{array}{l}\text { Vector containing only fundamental components } \\
\text { of } \mathbf{K}_{1}\end{array}$ \\
\hline $\mathbf{K}_{2}$ & $\begin{array}{l}\text { Vector does not containing the components of } \\
\text { rank } n q, q=1,2, \cdots \text { which exist in } \mathbf{K}_{1}\end{array}$ \\
\hline$\theta$ & Mechanical rotor angle \\
\hline & Mechanical rotor speed \\
\hline$C_{\text {total }}(p \theta)$ & Total torque \\
\hline$C_{e m}(p \theta)$ & Electromagnetic torque \\
\hline$C_{\operatorname{cog}}(p \theta)$ & Cogging torque \\
\hline$C_{r e f}$ & Desired torque \\
\hline
\end{tabular}

Manuscript received June 5, 2012. Revised October 19, 2012 and January 21, 2013. Accepted for publication February 13, 2013.

Copyright (c) 2009 IEEE. Personal use of this material is permitted. However, permission to use this material for any other purposes must be obtained from the IEEE by sending a request to pubs-permissions@ieee.org.

D. Flieller and G. Sturzer are with the GREEN Laboratory, INSA of Strasbourg, France, e-mail: [damien.flieller, guy.sturtzer]@insa-strasbourg.fr.

N. K. Nguyen is with the L2EP Laboratory, Arts et Métiers ParisTech, Lille Cedex, France, email: NgacKy.NGUYEN@ensam.eu.

P. Wira, D. Ould Abdeslam and J. Mercklé are with the MIPS Laboratory, University of Haute Alsace, France, email: [patrice.wira, djaffar.ouldabdeslam, jean.merckle]@uha.fr.

$\begin{array}{ll}\Omega_{\text {ref }} & \text { Desired speed } \\ k_{\text {opt-i}} & \text { Optimal function by strategy } i=0,1,2 \\ \mathbf{i}_{\text {opt }-i} & \text { Stator current vector corresponding to strategy } \\ & i=0,1,2\end{array}$

\section{INTRODUCTION}

\section{$\mathrm{P}$} ermanent Magnet Synchronous Motors

(PMSMs) are widely used in many industrial production systems due to their attractive features which are their compactness, high torque mass ratio, high efficiency and ease to be controlled. There are mainly two principal types of PMSMs which are characterized by sinusoidal or non-sinusoidal back electromotive forces (back-EMF) [1].

Whatever the PMSMs, torque ripples come from various causes [1]-[5]. The cogging torque is generated by the interaction between the rotor magnetic field and the stator teeth even if there is no current in the stator. Another source of torque pulsation results from the interaction between the stator currents and the rotor magnetic field. Generally, this torque can be divided into two terms. The first one is due to the rotor's magnets and the stator currents. The second one is due to the saillance. In this paper, only the first term is considered because our interest points to the non-saillance motor. Works related to saillance motors can be found in [6]-[8].

A constant torque is highly required in many applications. Therefore, various works were proposed to minimize the undesirable torque ripple [9]-[11]. These works can be divided into two categories. The techniques from the first one consist in developing the machine's stator and rotor design to cancel the undesirable torque ripple. The magnets's properties and how to distribute them optimally on the rotor's surface are studied in [5], [12]-[14]. The influence of the slots/poles ratio of the machine on the torque ripple is specifically studied in [13]. In [15], four analytical models for predicting the cogging torque in surface-mounted Permanent Magnet (PM) machines. This work focus on the influence of design parameters, such as the slot-depth-to-slot-opening ratio and optimal pole-arc-topole-pitch and slot-opening-to-slot-pitch ratios, on the cogging torque. The techniques from the second category are based on the stator current control. An analyze of the torque's expression is used to calculate the best currents that cancel the torque ripple. The literature provides various techniques for the optimal current determination according to adequate transformations. For example, the individual harmonics of the 
Fourier's series of the back-EMF are used in order to obtain the stator currents in [16]-[18]. The work presented in [16] optimizes the currents only for harmonics of rank 5 and 7 while the method presented in [17], [18] gives the optimal currents by calculating a pseudo-inverse matrix containing the harmonics of the back-EMF. A formula was proposed in [19] which works in the $a-b-c$ reference frame. In this method the homopolar current is null and moreover, the loss by Joule effect is not optimal. Always in the $a-b-c$ reference frame, the works presented in [20], [21] give the expressions of the optimal currents. These methods are based on a Lagrange's optimization to obtain the currents which minimize the stator ohmic losses and maintain the desired torque. While working in the $d-q$ reference frame of Park, the authors in [22], [23] determine the expressions of the $d-q$ optimal currents; [23] optimizes only for one harmonic of rank 6. A direct expression of the $a-b-c$ currents is given in [24], [25] by using an extension of Park's transformation. In [26], an adaptive process based on the Fourier series expansion is presented for a machine containing 4 pairs of poles and 24 stator slots. The flow chart proposed leads to the determination of the current $i_{q}(p \theta)$ in order to compensate for the $6^{\text {th }}$ rank harmonic of the torque ripple. The repetitive and iterative learning control schemes were presented in [4], [27]. Based on a vectorial approach, the generation of optimal current references for multiphase PMSM in real time is reported in [28]. This approach reduces the computing operations compared to scalar methods which generally require a large amount of calculus. The performance of the proposed method is experimentally valided in normal and fault mode (open-circuited phases). Zhao et al. in [29] recently presented an approach based on harmonic current injection, on which the Redundant Flux-Switching PermanentMagnet Motor (R-FSPM) can be operated with high dynamic performance and good behavior at steady-state. If the backEMF of the R-FSPM is highly non-sinusoidal, then the current calculation with the proposed method becomes complicated.

The work presented in this paper is different from the approaches mentioned above. A torque control scheme and a speed control scheme are proposed to cancel the torque ripple, including the cogging torque. The design of the controllers is based on Adaline Neural Networks (ANNs) [30], [31]. Indeed, the learning capabilities of the ANNs allow to calculate the optimal currents which give exactly the desired torque (or a desired speed) and minimum ohmic losses. This solution can be applied for a multiphase PM machine under normal operation or under open-circuit fault conditions.

This paper is organized as follows. The problem related to torque pulsation due to the harmonics of the back-EMF is presented in Section II. Section III presents new geometrical considerations leading to the optimal currents. They are based on the definition of hyperplanes whose equations depend on stator currents. Section IV proposes an original direct torque (or speed) controller based on an Adaline neural network. Simulation results in Section V and experimental results in Section VI confirm the validity of the proposed neural approach. Finally, concluding remarks are provided in Section VII.

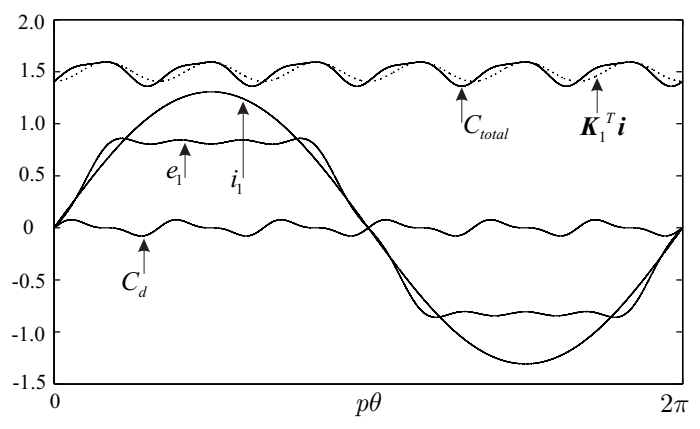

Fig. 1. Torque obtained in a non-sinusoidal three-phase machine in BLAC mode

\section{PMSM’s TORQUE RIPPLE}

The stator current and the back-EMF vectors of a $n$ phases PMSM can be defined respectively by:

$$
\begin{aligned}
\mathbf{i} & =\left[\begin{array}{llllll}
i_{1} & i_{2} & \cdots & i_{i} & \ldots & i_{n}
\end{array}\right]^{T}, \\
\mathbf{e} & =\left[\begin{array}{llllll}
e_{1} & e_{2} & \cdots & e_{i} & \ldots & e_{n}
\end{array}\right]^{T} .
\end{aligned}
$$

If the machine is non-sinusoidal, we can develop the backEMF for the $i^{\text {th }}$ phase as:

$$
e_{i}=\sum_{k=1}^{k_{\max }} e_{a k, i} \sin (k p \theta)+e_{b k, i} \cos (k p \theta), \quad i=1, \cdots, n,
$$

and the fundamental component of $e_{i}$ is:

$$
e_{i}^{0}=e_{a 1, i} \sin (p \theta)+e_{b 1, i} \cos (p \theta), \quad i=1, \cdots, n,
$$

where $k_{\max }$ is the highest considered harmonic of the backEMF, $\theta$ is the angular position, $e_{a k, i}$ and $e_{b k, i}$ are the Fourier coefficients. $p$ is the number of pole pairs.

The speed normalized back-EMF vector $\mathbf{K}_{1}$ can be expressed by:

$$
\mathbf{K}_{1}=\frac{1}{\Omega}\left[\begin{array}{llllll}
e_{1} & e_{2} & \cdots & e_{i} & \cdots & e_{n}
\end{array}\right]^{T} .
$$

We can define $\mathbf{K}_{0}$ by:

$$
\mathbf{K}_{0}=\frac{1}{\Omega}\left[\begin{array}{llllll}
e_{1}^{0} & e_{2}^{0} & \cdots & e_{i}^{0} & \cdots & e_{n}^{0}
\end{array}\right]^{T},
$$

where $\Omega=\frac{d \theta}{d t}$ is the rotor's speed.

The total torque of the machine is given by:

$$
C_{\text {total }}(p \theta)=C_{e m}(p \theta)+C_{c o g}(p \theta),
$$

with $C_{e m}(p \theta)=\mathbf{K}_{1}^{T} \mathbf{i}$ which represents the electromagnetic torque of the interaction between the stator currents and the rotor's magnetic field. Fig. 1 shows the current and the backEMF of phase 1 as well as the total torque of a non-sinusoidal three-phase machine. It is obvious that the sinusoidal excitation currents reveal a torque pulsation. To supply the machine correctly, we have to determine the stator current for each phase such that the desired torque $C_{r e f}$ is obtained. 
TABLE I

RELATIVE ANGULAR FREQUENCIES OF THE COGGING TORQUE PULSATIONS IN A THREE-PHASE PMSM $(n=3)$ [32], [34]

\begin{tabular}{|l|c|c|l|}
\hline Winding & $N_{s}$ & $2 p$ & angular frequencies $m l p$ of $C_{c o g}$ \\
\hline Distributed & 18 & 6 & $18,36,54, \ldots$ \\
& 36 & 6 & $36,72,108 \ldots$ \\
\hline \multirow{3}{*}{ Concentrated } & 9 & 6 & $18,36,54, \ldots$ \\
& 12 & 10 & $60,120,180 \ldots$ \\
& 12 & 14 & $84,168,252, \ldots$ \\
\hline
\end{tabular}

$C_{c o g}$ is the cogging torque which can be expressed by [12], [32], [33]:

$$
\begin{aligned}
C_{c o g}(p \theta) & =\sum_{l=1}^{l_{\max }} C_{c o g a, m l} \sin (m l p \theta)+C_{\operatorname{cog} b, m l} \cos (m l p \theta) \\
& =\sum_{l=1}^{l_{\max }} C_{c o g, m l} \cos \left(m l p \theta+\varphi_{m l}\right), l=1,2,3 \ldots
\end{aligned}
$$

where $m p$ is the least common multiple of the number of stator slots $N_{s}$ and the number of poles. We have:

$$
\begin{aligned}
C_{\operatorname{cog}, m l} & =\sqrt{C_{\operatorname{cog} a, m l}^{2}+C_{\operatorname{cog} b, m l}^{2}}, \\
\tan \varphi_{m l} & =-\frac{C_{\operatorname{cog} a, m l}}{C_{\operatorname{cog} b, m l}} .
\end{aligned}
$$

Tab. I gives the angular frequencies of the pulsation of the cogging torque in a three-phase machine $(n=3)$ for several feasible combinations of slot number and pole number of PMSM [32], [34].

Our goal is to cancel the torque ripple and we'll obtain:

$$
C_{\text {total }}(p \theta)=C_{\text {ref }} .
$$

From now, a torque analysis is necessary to design an efficient controller. Indeed, we want to establish a relationship between the back-EMF and the torque. This allows to determine the coefficients of the current harmonic terms and therefore allows to eliminate several or all undesirable torque harmonic terms. In steady state, when the stator current is:

$$
i_{i}=\sum_{h=1}^{h_{\max }} i_{a h, i} \sin (h p \theta)+i_{b h, i} \cos (h p \theta), \quad i=1, \cdots, n,
$$

the electromagnetic torque is then given by:

$C_{e m}(p \theta)=C_{0}+\sum_{q=1}^{q_{\max }} C_{a, q n^{\prime}} \sin \left(q n^{\prime} p \theta\right)+C_{b, q n^{\prime}} \cos \left(q n^{\prime} p \theta\right)$,

where $n^{\prime}=2 n$ if the back-EMF contains only odd or even harmonic components, $h_{\max }$ and $q_{\max } n^{\prime}$ are the highest harmonics of stator currents and electromagnetic torque respectively. In the general case, when the back-EMF contains both odd and even harmonic terms, we have $n^{\prime}=n$. This analyze is obtained by an extension of the work presented in [17]. $C_{0}$ is the mean value and $C_{a, q n^{\prime}}, C_{b, q n^{\prime}}$ are the Fourier coefficients of $C_{e m}(p \theta) . q_{\max }$ is determined by:

$$
q_{\max }=\operatorname{integer}\left(\frac{k_{\max }+h_{\max }}{n^{\prime}}\right) .
$$

TABLE II

RELATIVE ANGULAR FREQUENCY OF THE TORQUE PULSATIONS IN A THREE-PHASE PMSM $(n=3)$ [33]

\begin{tabular}{c|cccccccccc}
$\mathrm{h}$ & $\mathrm{k}$ & 1 & 3 & 5 & 7 & 9 & 11 & 13 & 15 & 17 \\
\cline { 2 - 9 } 1 & & & & 6 & 6 & & 12 & 12 & & 18 \\
3 & & & 0,6 & & & 6,12 & & & 12,18 & \\
5 & & 6 & & 0 & 12 & & 6 & 18 & & \\
7 & & 6 & & 12 & 0 & & 18 & 6 & & 24 \\
9 & & & 6,12 & & & 0,18 & & & 6,24 & \\
11 & 12 & & 6 & 18 & & 0 & 24 & & 6 \\
13 & 12 & & 18 & 6 & & 24 & 0 & & 30 \\
15 & & 12,18 & & & 24 & & & 0,30 & \\
17 & 18 & & 12 & 24 & & 6 & 30 & & 0 \\
19 & 18 & & 24 & 12 & & 30 & 6 & & 36 \\
21 & & 18,24 & & & 12,30 & & & 6,36 &
\end{tabular}

We note:

$$
C_{q n^{\prime}}=\sqrt{C_{a, q n^{\prime}}^{2}+C_{b, q n^{\prime}}^{2}}
$$

The compensation of the torque ripple leads to:

$$
C_{0}=C_{r e f}
$$

and this condition is obtained when:

$$
\sum_{q=1}^{q_{\max }} C_{a, q n^{\prime}} \sin \left(q n^{\prime} p \theta\right)+C_{b, q n^{\prime}} \cos \left(q n^{\prime} p \theta\right)=-C_{\operatorname{cog}}(p \theta) .
$$

The torque pulsations produced by the stator current components $h$ and the back-EMF components $k$ for a three-phase machine are given by Tab. II [33]. It is obvious that a nonsinusoidal PMSM exited by sinusoidal currents gives a torque pulsation. In order to supply the machine correctly, the stator current for each phase must be determined so that:

$$
\mathbf{K}_{1}^{T} \mathbf{i}=C_{r e f}-C_{\operatorname{cog}}(p \theta) .
$$

There is an infinity of solutions $\mathbf{i}$ for (18) and we aim to obtain one giving a minimum ohmic losses. In [21], [22], [35], [36], solutions are obtained from an optimization based on Lagrange's method to derive the stator currents. The work presented thereafter will complete these solutions by using a geometrical approach to deduce the optimal currents. Furthermore, the optimal currents can be easily obtained by a feed-back current control scheme based on an Adaline neural network. It should be noticed that these currents give exactly the desired torque by taking into account the cogging torque.

\section{GEOMETRICAL INTERPRETATION OF THE THREE OPTIMAL CURRENTS}

(18) is an equation of a hyperplane. Let $P$ be the hyperplane that contains all points $M$ whose coordinates are equal to $\mathbf{i}$ and which satisfies (18). $\mathbf{K}_{1}$ is thus normal to $P$.

In the case of a star coupled machine, the zero homopolar current constraint can be introduced by:

$$
\mathbf{u}_{1}^{T} \mathbf{i}=0,
$$

with $\mathbf{u}_{1}=\left[\begin{array}{llll}1 & 1 & \cdots & 1\end{array}\right]^{T},\left\|\mathbf{u}_{1}\right\|^{2}=n$.

(18) is also an equation of an other hyperplane. Let $H_{1}$ be a second hyperplane where all points $M$ verify (19). $\mathbf{u}_{1}$ is thus normal to $H_{1} . P$ and $H_{1}$ are represented on Fig. 2. 


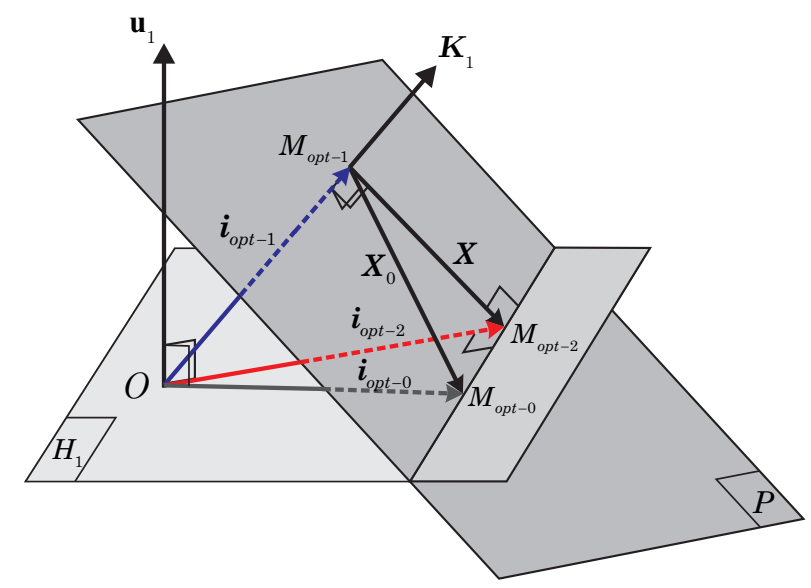

Fig. 2. Geometrical representation of the three optimal current vectors $\mathbf{i}_{\text {opt }-0}, \mathbf{i}_{\text {opt }-1}, \mathbf{i}_{\text {opt }-2}$

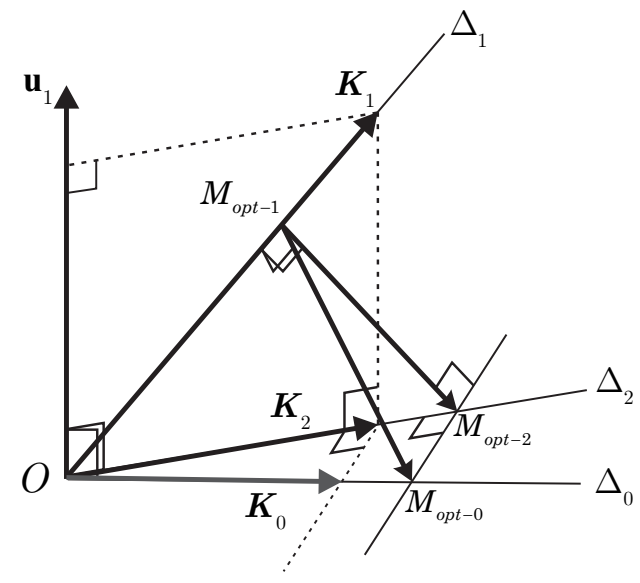

Fig. 3. Geometrical representation of the three vectors $\mathbf{K}_{0}, \mathbf{K}_{1}$, and $\mathbf{K}_{2}$

First, we try to find $\mathbf{i}=\mathbf{i}_{\text {opt-0 }}$ proportional to $\mathbf{K}_{0}$ :

$$
\mathbf{i}_{\text {opt-0 }}=k_{\text {opt-0}} \mathbf{K}_{0} \text {. }
$$

From (18) and (20), we have:

$$
k_{\text {opt }-0}=\frac{C_{r e f}-C_{\operatorname{cog}}(p \theta)}{\mathbf{K}_{1}^{T} \mathbf{K}_{0}},
$$

and finally, we obtain:

$$
\mathbf{i}_{\text {opt }-0}=\frac{C_{r e f}-C_{\operatorname{cog}}(p \theta)}{\mathbf{K}_{0}^{T} \mathbf{K}_{1}} \mathbf{K}_{0}=\frac{C_{r e f}-C_{\operatorname{cog}}(p \theta)}{\mathbf{K}_{1}^{T} \mathbf{K}_{0}} \mathbf{K}_{0} .
$$

The current of the $i^{\text {th }}$ phase is therefore:

$$
i_{o p t-0, i}=\frac{C_{r e f}-C_{c o g}(p \theta)}{\sum_{k=1}^{n} e_{k} e_{k}^{0}} \Omega e_{i}^{0} .
$$

It should be noticed that $\mathbf{i}_{\text {opt-0 }}$ always gives a zero homopolar current. This solution is represented by the point $M_{o p t-0}$ on Fig. 2. $\mathbf{i}_{o p t-0}$ does not give the minimal ohmic losses. Let us define $M_{o p t-1}$, represented on Fig. 2, that belongs to the hyperplane $P$ and is nearest point to the origin $O$. We will show that taking some geometrical considerations allows to easily derive the expression of the current vector $\mathbf{i}_{o p t-1}$, corresponding to $M_{o p t-1}$, which has the minimal module. The current $\mathbf{i}_{\text {opt-1 }}$ is thus proportional to $\mathbf{K}_{1}$, so:

$$
\mathbf{i}_{o p t-1}=\left(\frac{\mathbf{K}_{1}^{T}}{\left\|\mathbf{K}_{1}\right\|} \mathbf{i}_{o p t-1}\right) \frac{\mathbf{K}_{1}}{\left\|\mathbf{K}_{1}\right\|}
$$

with $\frac{\mathbf{K}_{1}}{\left\|\mathbf{K}_{1}\right\|}$ is the unit vector in the direction of $\mathbf{K}_{1}$. From (18), we have $\mathbf{K}_{1}^{T} \mathbf{i}_{\text {opt-1 }}=\mathbf{K}_{1}^{T} \mathbf{i}_{\text {opt-0 }}$, and (24) becomes:

$$
\mathbf{i}_{\text {opt-1 }}=\left(\frac{\mathbf{K}_{1}^{T}}{\left\|\mathbf{K}_{1}\right\|} \mathbf{i}_{\text {opt-0 }}\right) \frac{\mathbf{K}_{1}}{\left\|\mathbf{K}_{1}\right\|},
$$

and with $\mathbf{K}_{1}^{T} \mathbf{K}_{1}=\left\|\mathbf{K}_{1}\right\|^{2}$, we obtain:

$$
\begin{aligned}
\mathbf{i}_{o p t-1} & =\left(C_{r e f}-C_{\operatorname{cog}}(p \theta)\right) \frac{\mathbf{K}_{1}^{T} \mathbf{K}_{0}}{\mathbf{K}_{1}^{T} \mathbf{K}_{0}} \frac{\mathbf{K}_{1}}{\left\|\mathbf{K}_{1}\right\|^{2}} \\
& =\frac{C_{r e f}-C_{\operatorname{cog}}(p \theta)}{\mathbf{K}_{1}^{T} \mathbf{K}_{1}} \mathbf{K}_{1} .
\end{aligned}
$$

$\mathbf{i}_{\text {opt-1 }}$ gives the minimal ohmic losses and the $i^{\text {th }}$ phase can be written as follow:

$$
i_{o p t-1, i}=\frac{C_{r e f}-C_{c o g}(p \theta)}{\sum_{k=1}^{n} e_{k}^{2}} \Omega e_{i} .
$$

In a star connected machine, we have to introduce the additional constraint given by (19).

Let us define $M_{o p t-2}$, represented on Fig. 2, that belongs to the intersection of $H_{1}$ and $P$ and is nearest to the origin $O$. Once again, we will show that taking some geometrical considerations allows to easily derive the expression of the current vector $\mathbf{i}_{o p t-2}$, corresponding to $M_{o p t-2}$, which has the minimal module.

The current $\mathbf{i}_{\text {opt-2 }}$ is proportional to $\mathbf{K}_{2}$ :

$$
\mathbf{i}_{\text {opt-2 }}=\left(\frac{\mathbf{K}_{2}^{T}}{\left\|\mathbf{K}_{2}\right\|} \mathbf{i}_{\text {opt-2 }}\right) \frac{\mathbf{K}_{2}}{\left\|\mathbf{K}_{2}\right\|},
$$

where $\mathbf{K}_{2}$ is determined by (Fig. 3):

$$
\mathbf{K}_{2}=\mathbf{K}_{1}-\frac{\mathbf{K}_{1}^{T} \mathbf{u}_{1}}{\left\|\mathbf{u}_{1}\right\|^{2}} \mathbf{u}_{1}=\mathbf{K}_{1}-\mathbf{u}_{1}^{T} \mathbf{K}_{1} \frac{\mathbf{u}_{1}}{n} .
$$

It can be seen from (29) that $\mathbf{K}_{2}$ does not contain harmonics components of rank $n q, q=1,2, \cdots$ which exist in the vector $\mathbf{K}_{1} . \mathbf{K}_{2}$ can thus be expressed by:

$$
\mathbf{K}_{2}=\frac{1}{\Omega}\left[\begin{array}{llllll}
e_{1}^{\prime} & e_{2}^{\prime} & \cdots & e_{i}^{\prime} & \cdots & e_{n}^{\prime}
\end{array}\right]^{T},
$$

where:

$$
\begin{aligned}
e_{i}^{\prime} & =e_{i}-\frac{1}{n} \sum_{k=1}^{k_{\max }} e_{k} \\
& =\sum_{k=1, k \neq n q}^{k_{\max }^{\prime}} e_{a k, i} \sin (k p \theta)+e_{b k, i} \cos (k p \theta), \quad i=1, \ldots, n .
\end{aligned}
$$

$k_{\max }^{\prime}$ is the highest component of $e_{i}^{\prime}$ and $k_{\max }^{\prime}=k_{\max }$ when $k_{\max } \neq n q$.

From (18), we have:

$$
\mathbf{K}_{1}^{T} \mathbf{i}_{\text {opt-2 }}=\mathbf{K}_{1}^{T} \mathbf{i}_{\text {opt-0 }}
$$


where:

$$
\begin{aligned}
\mathbf{K}_{1}^{T} \mathbf{i}_{\text {opt-2 }} & =\left(\mathbf{K}_{2}+\frac{\mathbf{K}_{1}^{T} \mathbf{u}_{1}}{\left\|\mathbf{u}_{1}\right\|^{2}} \mathbf{u}_{1}\right)^{T} \mathbf{i}_{\text {opt-2 }}=\mathbf{K}_{2}^{T} \mathbf{i}_{\text {opt-2 }} \\
\mathbf{K}_{1}^{T} \mathbf{i}_{\text {opt }-0} & =\left(\mathbf{K}_{2}+\frac{\mathbf{K}_{1}^{T} \mathbf{u}_{1}}{\left\|\mathbf{u}_{1}\right\|^{2}} \mathbf{u}_{1}\right)^{T} \mathbf{i}_{\text {opt }-0}=\mathbf{K}_{2}^{T} \mathbf{i}_{\text {opt }-0}
\end{aligned}
$$

We can thus deduce:

$$
\mathbf{K}_{2}^{T} \mathbf{i}_{o p t-2}=\mathbf{K}_{2}^{T} \mathbf{i}_{o p t-0} .
$$

From (22) and (35), the expression (28) becomes:

$$
\begin{aligned}
\mathbf{i}_{o p t-2} & =\left(\frac{\mathbf{K}_{2}^{T}}{\left\|\mathbf{K}_{2}\right\|} \mathbf{i}_{\text {opt-0 }}\right) \frac{\mathbf{K}_{2}}{\left\|\mathbf{K}_{2}\right\|} \\
& =\left(\frac{\mathbf{K}_{2}^{T} \mathbf{K}_{0}}{\mathbf{K}_{2}^{T} \mathbf{K}_{2}} \frac{C_{r e f}-C_{c o g}(p \theta)}{\mathbf{K}_{1}^{T} \mathbf{K}_{0}}\right) \mathbf{K}_{2} .
\end{aligned}
$$

From (29), we obtain:

$$
\mathbf{K}_{2}^{T} \mathbf{K}_{0}=\mathbf{K}_{1}^{T} \mathbf{K}_{0} .
$$

Moreover, from the Pythagorean theorem:

$$
\mathbf{K}_{2}^{T} \mathbf{K}_{2}=\mathbf{K}_{1}^{T} \mathbf{K}_{1}-\frac{\left(\mathbf{K}_{1}^{T} \mathbf{u}_{1}\right)^{2}}{\left\|\mathbf{u}_{1}\right\|^{2}}=\mathbf{K}_{1}^{T} \mathbf{K}_{2}=\mathbf{K}_{2}^{T} \mathbf{K}_{1} .
$$

According to (37) and (38), $\mathbf{i}_{\text {opt-2 }}$ is obtained as follow:

$$
\mathbf{i}_{o p t-2}=\frac{C_{r e f}-C_{\operatorname{cog}}(p \theta)}{\mathbf{K}_{1}^{T} \mathbf{K}_{2}} \mathbf{K}_{2} .
$$

The expression for the $i^{\text {th }}$ phase current $\mathbf{i}_{\text {opt-2 }}$ is given by:

$$
\begin{aligned}
i_{\text {opt }-2, i} & =\frac{C_{r e f}-C_{\operatorname{cog}}(p \theta)}{\sum_{k=1}^{n}\left(e_{k}-\frac{1}{n} \sum_{l=1}^{n} e_{l}\right)^{2}}\left(e_{i}-\frac{1}{n} \sum_{l=1}^{n} e_{l}\right) \Omega \\
& =\frac{C_{r e f}-C_{\operatorname{cog}}(p \theta)}{n \sum_{k=1}^{n} e_{k}{ }^{2}-\left(\sum_{k=1}^{n} e_{k}\right)^{2}}\left(n e_{i}-\sum_{l=1}^{n} e_{l}\right) \Omega .
\end{aligned}
$$

$\mathbf{i}_{o p t-2}$ is the current vector which offers less ohmic losses with zero homopolar current.

This section has developed the expressions of optimal currents which are already presented in various works by using different approaches. Indeed, $\mathbf{i}_{\text {opt-0 }}$ is identical to the solution given in [19]. Based on the Lagrange's optimization, the currents $\mathbf{i}_{\text {opt-1 }}$ and $\mathbf{i}_{\text {opt-2 }}$ are also obtained in [21], [22], [37]. Our solution leads to the same results. We give a completed geometrical representation on which we can easily determine these different optimal currents.

Expressions (22) (26) and (39) can be generalized to faulty conditions. In the faulty phases, the current can be null (open circuit), equal to a saturation value, or be a short-circuit current. The current of the healthy phases can be calculated if the defect conditions are known by imposing the desired torque, minimizing Joule losses, and fulfilling the constraints on the homopolar current (free or null). But, it is difficult to determine in real time the cogging torque and the nature of the fault. A learning schemes based on an Adaline network is thus proposed as a torque controller to provide the Fourier's

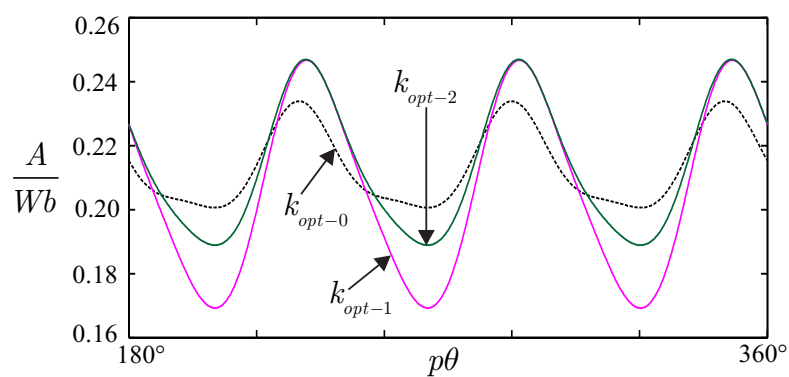

Fig. 4. Three optimal functions $k_{o p t-i}$ in non-sinusoidal back-EMF vectors

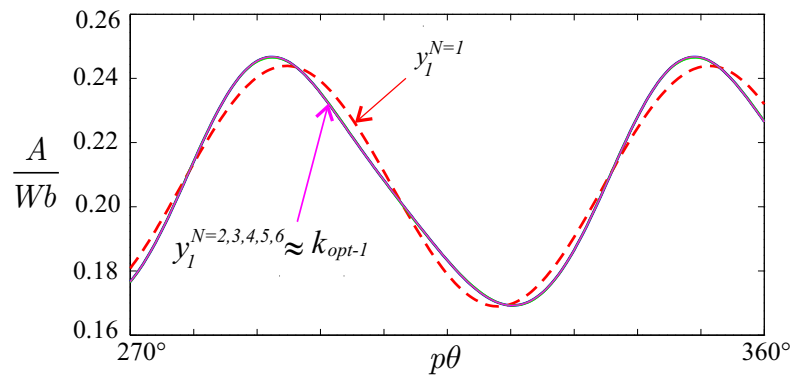

Fig. 5. Optimal function $k_{o p t-1}$ obtained for different values of $N$ $\left(m l_{\max }=12, q_{\max } n^{\prime}=12, q_{\max } n^{\prime}=18\right.$ is negligible $)$

coefficients of an optimal function. This technique will thus be able to calculate the desired optimal currents on real time. This main contribution is presented in the following section.

\section{TORQUE AND SPEED CONTROLLERS BASED ON ADALINE NEURAL NETWORKS}

\section{A. Principal ideas for the torque and speed control}

The optimal current is a product between $k_{o p t-i}(p \theta)$ with the vector $\mathbf{K}_{i}, i=0,1,2$. The optimal currents $\mathbf{i}_{\text {opt }-i}$ can be rewritten as:

$$
\begin{aligned}
& \mathbf{i}_{\text {opt-0 }}=\frac{C_{r e f}-C_{\operatorname{cog}}(p \theta)}{\mathbf{K}_{1}^{T} \mathbf{K}_{0}} \mathbf{K}_{0}=k_{o p t-0}(p \theta) \mathbf{K}_{0}, \\
& \mathbf{i}_{o p t-1}=\frac{C_{r e f}-C_{\operatorname{cog}}(p \theta)}{\mathbf{K}_{1}^{T} \mathbf{K}_{1}} \mathbf{K}_{1}=k_{o p t-1}(p \theta) \mathbf{K}_{1}, \\
& \mathbf{i}_{\text {opt-2 }}=\frac{C_{r e f}-C_{c o g}(p \theta)}{\mathbf{K}_{1}^{T} \mathbf{K}_{2}} \mathbf{K}_{2}=k_{o p t-2}(p \theta) \mathbf{K}_{2} .
\end{aligned}
$$

Fig. 4 gives the shapes of the three optimal functions $k_{o p t-i}$ corresponding to a cogging torque and to a non-sinusoidal back-EMF (the Fourier's components of the back-EMF are given in section $\mathrm{V}-\mathrm{A}$ ).

The optimal functions $k_{o p t-i}(p \theta)$ with $i=0,1,2$ can be written by a sum of Fourier's terms as follow:

$k_{\text {opt-i }}=k_{0-i}+\sum_{q=1}^{N}\left(k_{a q n^{\prime}-i} \sin \left(q n^{\prime} p \theta\right)+k_{b q n^{\prime}-i} \cos \left(q n^{\prime} p \theta\right)\right)$.

The functions $k_{\text {opt-i }}(i=0,1,2)$ will be learned and synthesized by an Adaline network.

The value of $N$ is important in order to compensate for the torque ripple and has to be determined correctly. This 


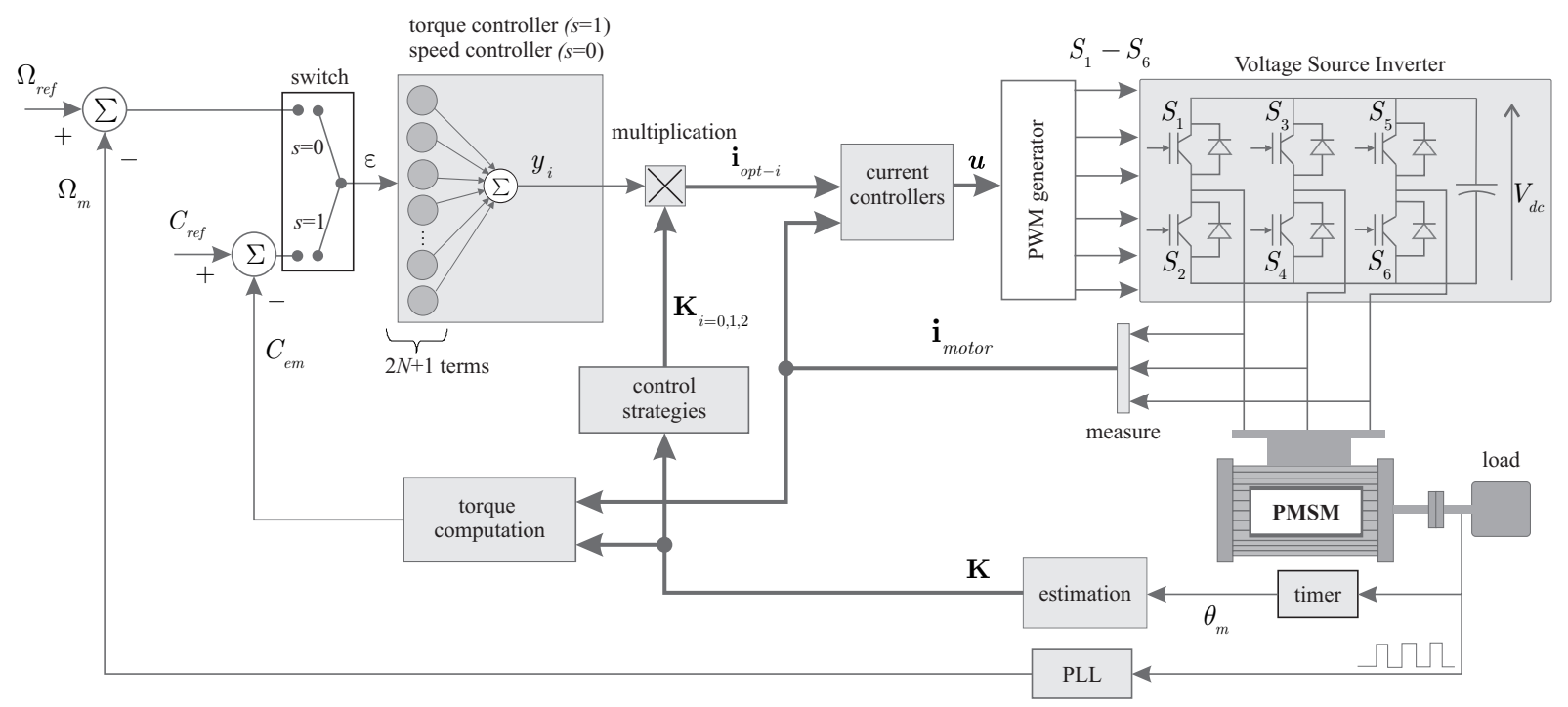

Fig. 6. Torque or speed control scheme for a PMSM based on an Adaline neural network

value can be obtained after a mathematical decomposition of the optimal function $k_{o p t-i}$. We present the development of $k_{o p t-1}$. Based on the value of $N$ for $k_{o p t-1}$, we can determine the ones for $k_{o p t-0}$ and $k_{o p t-2}$. Indeed, the product of $\mathbf{K}_{1}^{T} \mathbf{K}_{1}$ can be expressed as:

$$
\mathbf{K}_{1}^{T} \mathbf{K}_{1}=A_{0}+\sum_{q=1}^{q_{\max }} A_{q n^{\prime}} \cos \left(q n^{\prime} p \theta+\psi_{q n^{\prime}}\right)
$$

where $q_{\max }=\operatorname{int}\left(\frac{2 k_{\max }}{n^{\prime}}\right)$.

When the coefficients $A_{q n^{\prime}}<<A_{0}$, we can write:

$$
\frac{1}{\mathbf{K}_{1}^{T} \mathbf{K}_{1}} \approx \frac{1}{A_{0}}\left(1-\sum_{q=1}^{q_{\max }} \frac{A_{q n^{\prime}}}{A_{0}} \cos \left(q n^{\prime} p \theta+\psi_{q n^{\prime}}\right)\right) .
$$

Finally, we obtain:

$$
\begin{aligned}
k_{o p t-1}= & \frac{C_{r e f}-C_{c o g}(p \theta)}{\mathbf{K}_{1}^{T} \mathbf{K}_{1}} \\
= & \frac{C_{0}}{A_{0}}\left(1-\sum_{l=1}^{l_{\max }} \frac{C_{c o g, m l}}{C_{0}} \cos \left(m l p \theta+\varphi_{m l}\right)\right. \\
& \left.-\sum_{q=1}^{q_{\max }} \frac{A_{q n^{\prime}}}{A_{0}} \cos \left(q n^{\prime} p \theta+\psi_{q n^{\prime}}\right)\right) .
\end{aligned}
$$

By observing (47), we notice that the Adaline can estimate correctly the function $k_{o p t-1}$ if the input vector $\mathbf{x}$ contains all the terms presented in $k_{o p t-1}$. So, the highest rank of Adaline's input $\left(N n^{\prime}\right)$ has to be:

$$
N n^{\prime}=\max \left(m l_{\max }, \operatorname{int}\left(\frac{2 k_{\max }}{n^{\prime}}\right) n^{\prime}\right) .
$$

With the same development, we determine $N$ for the $k_{o p t-0}$ :

$$
N n^{\prime}=\max \left(m l_{\max }, \operatorname{int}\left(\frac{k_{\max }+1}{n^{\prime}}\right) n^{\prime}\right),
$$

and for the $k_{o p t-2}$ :

$$
N n^{\prime}=\max \left(m l_{\max }, \operatorname{int}\left(\frac{k_{\max }+k_{\max }^{\prime}}{n^{\prime}}\right) n^{\prime}\right) .
$$

Fig. 5 shows the estimation of $k_{\text {opt-1 }}$ with different values of $N$ (the machine's parameters are given in section $\mathrm{V}$ ). We can see that a good estimation is obtained when $N \geq 2$.

For the three strategies, the vector containing the Fourier coefficients must be determined:

$$
\mathbf{w}_{i}^{*}=\left[\begin{array}{llllll}
k_{0-i} & k_{a n^{\prime}-i} & k_{b n^{\prime}-i} & . . & k_{a N n^{\prime}-i} & k_{b N n^{\prime}-i}
\end{array}\right]^{T} .
$$

Based on this, a torque control and a speed control can be synthesized in one single scheme represented by Fig. 6 . The switch $s$ allows to choose between the torque control or the speed control ( $s=1$ or $s=0$ respectively) according to the inverter's characteristics and to the machine's coupling. The functions $k_{o p t-i}(i=0,1,2)$ will be learned and synthesized by the Adaline network of the controller based on the three possible strategies:

- Strategy 0: Only the fundamental component of the backEMF is used. This strategy can be used for all machines and all couplings with or without a neutral line.

- Strategy 1: The back-EMF is used completely, with all its harmonic components. This strategy can be used for star-coupled machines without a neutral line, which does not have harmonic components that are multiple of three in their back-EMFs, or all the machines that support a homopolar current.

- Strategy 2: The back-EMF is used without its harmonic component of rank multiple of $n$. This strategy can be used for all star-coupled machines without a neutral line. The Adaline controller takes the place of the traditional torque or speed controller for ensuring the convergence of the motor's torque or speed toward the desired ones. All the torque ripples are compensated. The details about the Adaline are presented in the next section $\left(\mathbf{K}_{i}\right.$ can be obtained off-line by another Adaline, see Section VI-A).

\section{B. Adaline-based controller design}

Adaline's structure is shown in Fig. 7. The rule of the torque or the speed controller based on the Adaline is to provide 


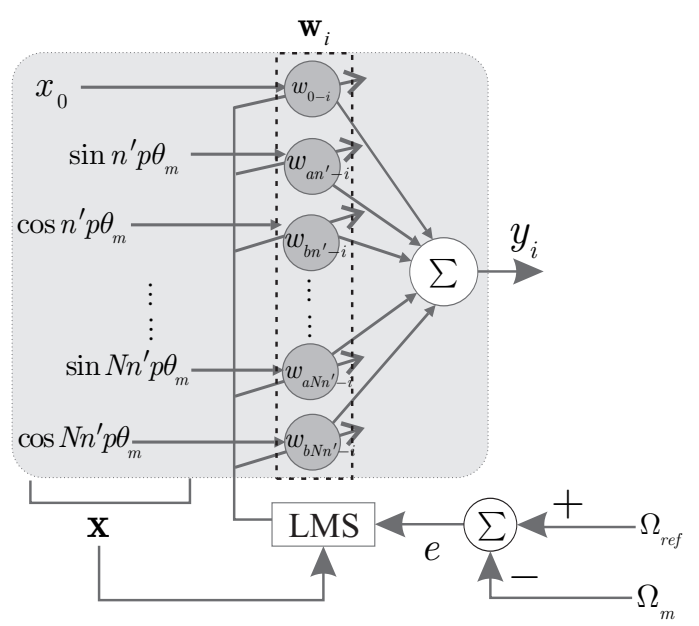

Fig. 7. Adaline-based torque or speed control

the optimal functions $k_{o p t-i}$ with $i=0,1,2$. The same input vector of the Adaline is used for the three strategies:

$$
\begin{aligned}
& \mathbf{x}=\left[\begin{array}{llll}
x_{0} & \sin \left(n^{\prime} p \theta\right) & \cos \left(n^{\prime} p \theta\right) & \cdots
\end{array}\right. \\
& \left.\sin \left(N n^{\prime} p \theta\right) \quad \cos \left(N n^{\prime} p \theta\right)\right]^{T}
\end{aligned}
$$

where $\theta$ is supposed to be close to $\theta_{m}$ which is measured by an encoder.

For each control strategy, the weights of Adaline are defined by:

$\mathbf{w}_{i}=\left[\begin{array}{llllll}w_{0-i} & w_{a n^{\prime}-i} & w_{b n^{\prime}-i} & . . & w_{a N n^{\prime}-i} & w_{b N n^{\prime}-i}\end{array}\right]^{T}$.

The output of Adaline is then:

$y_{i}=\mathbf{w}_{i}^{T} \mathbf{x}$

$=w_{0-i} x_{0}+\sum_{q=1}^{N}\left(w_{a q n^{\prime}-i} \sin \left(q n^{\prime} p \theta\right)+w_{b q n^{\prime}-i} \cos \left(q n^{\prime} p \theta\right)\right)$.

The Adaline weights are solved using an iterative linear Least Mean Squares (LMS) algorithm [38] in order to minimize the torque or speed error. The weights of the Adaline can be interpreted, giving thus a non negligible advantage to the Adaline over other types of ANNs. The Adaline is well-suited and ideal for approximating and learning linear relations. It will thus be used to learn the expressions previously developed. The Adaline weights are adjusted at each sampled time $k$ :

$$
\mathbf{w}_{i}(k+1)=\frac{\mathbf{w}_{i}(k)+\eta \epsilon \mathbf{x}}{\mathbf{x}^{T} \mathbf{x}}=\frac{\mathbf{w}_{i}(k)+\eta \epsilon \mathbf{x}}{x_{0}^{2}+N},
$$

where $\eta$ is a learning rate [38], $\epsilon$ is the torque or speed error.

On each iteration, the weights of Adaline are enforced to converge toward the amplitudes of current corresponding to the control strategy. After convergence,

$$
\mathbf{w}_{i}(k)_{k \rightarrow \infty}^{\longrightarrow} \mathbf{w}_{i}^{*},
$$

where $\mathbf{w}_{i}^{*}$ is the optimal solution given by (51). Finally, the output of Adaline $y_{i}$ converges toward $k_{o p t-i}$.
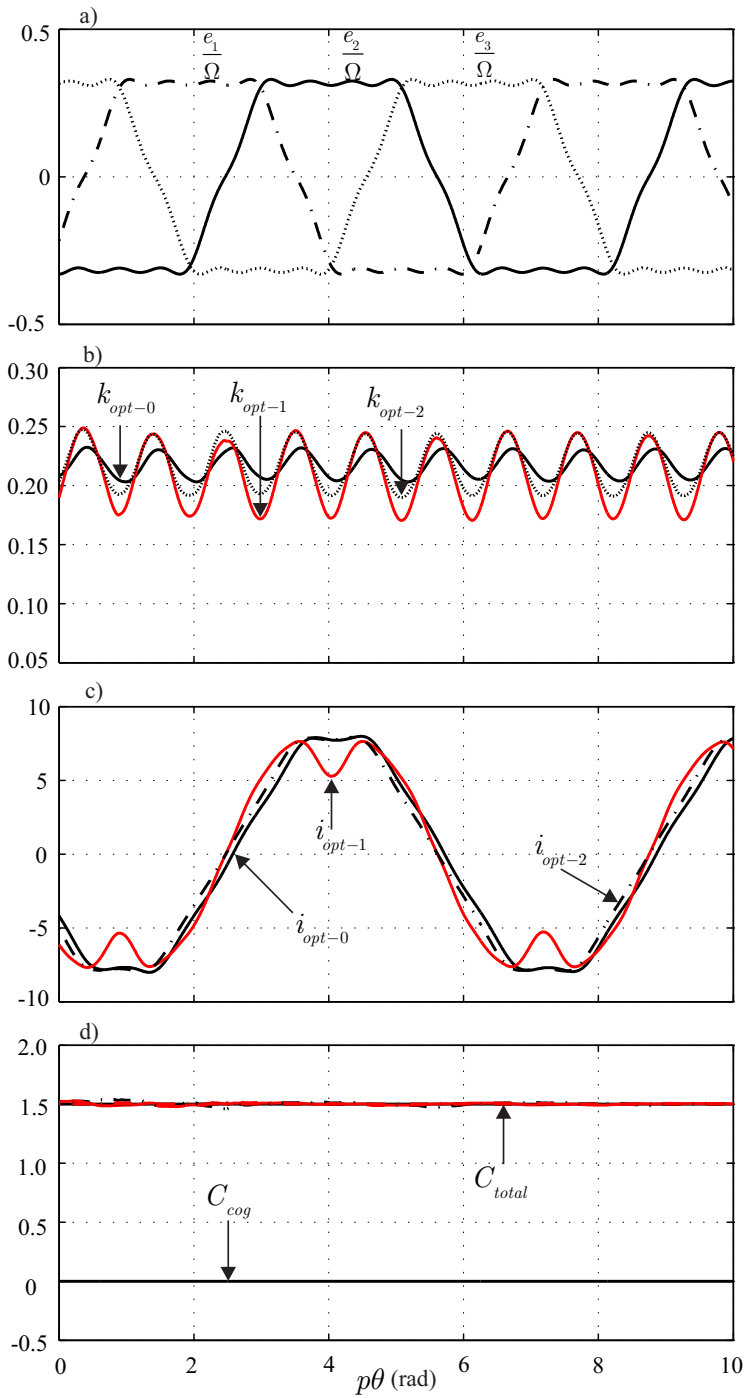

Fig. 8. Simulation results of a three-phase non-sinusoidal machine: a) $\Phi_{1}^{\prime}, \Phi_{2}^{\prime}, \Phi_{3}^{\prime}(\mathrm{Wb})$; b) $k_{o p t-0}, k_{o p t-1}$ and $k_{o p t-2}(\mathrm{~A} / \mathrm{Wb})$ obtained by the Adaline controller; c) optimal currents (one phase) obtained with three approaches (A); d) torque developed (N.m)

\section{Simulation Results}

In this section, simulation results are presented to evaluate and to compare the performances of the approaches previously developed. A non-sinusoidal three-phase PMSM $(n=3)$ is considered and a constant torque of $1.5 \mathrm{~N} . \mathrm{m}$ is desired.

\section{A. Case without a cogging torque}

The following numerical example is taken. The nonsinusoidal three-phase PMSM has no cogging torque and a speed normalized back-EMF for the first phase expressed by:

$$
\begin{aligned}
\frac{e_{1}(p \theta)}{\Omega} & =p \phi_{f 1} \sin (p \theta)+3 p \phi_{f 3} \sin (3 p \theta)+5 p \phi_{f 5} \sin (5 p \theta) \\
& +7 p \phi_{f 7} \sin (7 p \theta)+9 p \phi_{f 9} \sin (9 p \theta)
\end{aligned}
$$

with $\phi_{f 1}=0.1223 \mathrm{~Wb}, \phi_{f 3}=0.0258 \mathrm{~Wb}, \phi_{f 5}=0.0027$ $\mathrm{Wb}, \phi_{f 7}=-0.0049 \mathrm{~Wb}$, and $\phi_{f 9}=-0.0054 \mathrm{~Wb}$. In this case, $k_{\max }=9$ (according to (3)) and $k_{\max }^{\prime}=7$ according 


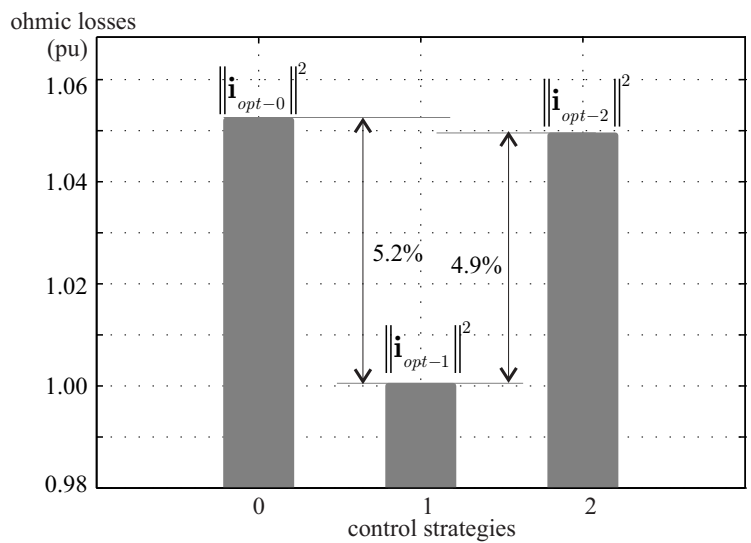

Fig. 9. Ohmic losses (in pu) given by the three torque control strategies
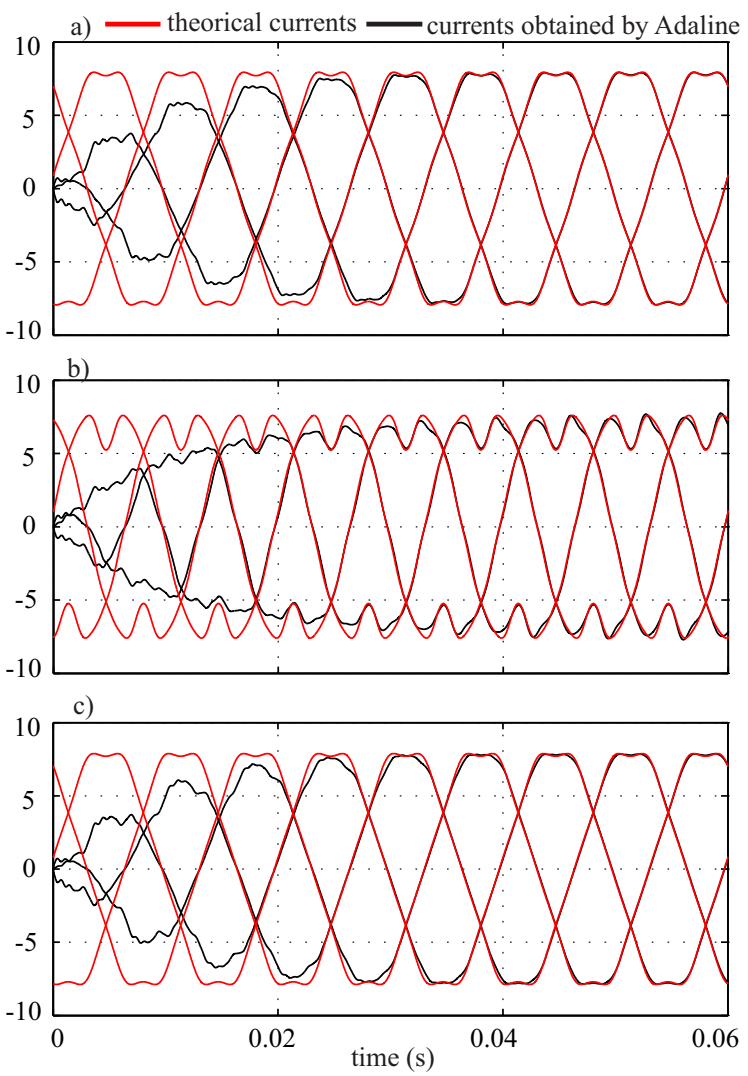

Fig. 10. a) $\mathbf{i}_{\text {opt-0 }}$ obtained with (41) learned by an Adaline ; b) $\mathbf{i}_{\text {opt-1 }}$ obtained with (42) learned by an Adaline; c) $\mathbf{i}_{o p t-2}$ obtained with (43) learned by an Adaline $(\Omega=314 \mathrm{rad} / \mathrm{s}$ and $\eta=0.1)$

to (31). $e_{1}$ contains only odd terms, the ranks of torque ripple is thus $2 q n=6 q$ and $q=1,2,3$.

According to (49), (48), (50), we chose $6 N=18$ to reach an optimal solution. Fig. 8 shows the performances of the neural torque control with $6 N=18$. More precisely, Fig. 8 a) shows the flux linkage, Fig. 8 b) shows the three optimal functions $k_{o p t-0}, k_{o p t-1}$ and $k_{o p t-2}$ obtained by the Adaline controller. Fig. $8 \mathrm{c}$ ) gives the shapes of the three optimal currents obtained with three strategies and Fig. 8 d) shows the total torque developed. It can be seen that the approach based on $\mathbf{i}_{o p t-0}$ gives the same results than the one based on $\mathbf{i}_{o p t-2}$ since these two currents are close.

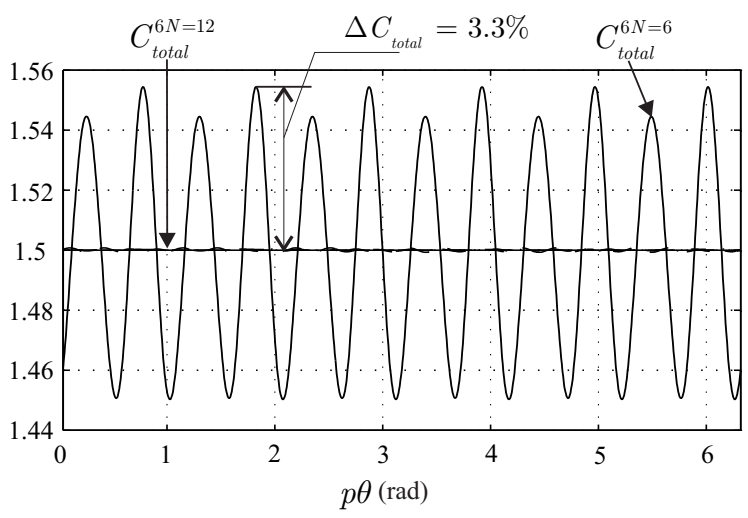

Fig. 11. Torques $C_{\text {total }}$ (N.m) obtained when $6 N=6$ and $6 N=12$ with strategy $\mathbf{i}_{o p t-2}$

The stator's ohmic losses have been estimated for the three approaches. Fig. 9 confirms that the ohmic losses obtained with $\mathbf{i}_{o p t-1}$ are minimum. The currents $\mathbf{i}_{o p t-0}$ present $5.2 \%$ more ohmic losses and the losses of $\mathbf{i}_{o p t-2}$ are lightly smaller. $\mathbf{i}_{o p t-2}$ are thus the optimal solution for a machine which does not have a homopolar current. Fig. 10 shows the currents $\mathbf{i}_{o p t-0}, \mathbf{i}_{o p t-1}$ and $\mathbf{i}_{o p t-2}$ obtained by learning respectively (41), (42) and (43) with an Adaline. We can see that the convergence of all strategies is obtained approximately in one round.

\section{B. Case with a cogging torque}

To clarify the performance of the proposed control strategy, a cogging torque is now introduced under the same previous conditions. Let us thus consider the following cogging torque:

$$
C_{\operatorname{cog}}(p \theta)=0.06 \sin (6 p \theta)+0.03 \sin (12 p \theta) .
$$

The simulated results with a cogging torque are shown by Fig. 11 which compares the total torques obtained for the strategy based on $\mathbf{i}_{o p t-2}$ with two cases, i.e., $6 N=6$ and $6 N=12$. This figure shows that for $6 N=6$, the torque of rank 6 is completely compensated but the torques of ranks 12 , 18 and 24 are only partially eliminated. Finally, the torque ripple results in $\Delta C_{\text {total }}=3.3 \%$. In the second case, it can be seen from the same figure that the torque ripples of rank 6,12 and 18 are perfectly eliminated for $6 N=12$. For this value of $N=2$, Fig. 12 shows the optimal functions and the optimal currents, $k_{o p t-i}$ and $\mathbf{i}_{o p t-i}$ with $i=0,1,2$, and the resulting torques. It can be seen that all torque ripple, including the cogging torque, is elimined. Finally, we have $C_{\text {total }}=C_{\text {ref }}=1.5$ N.m.

\section{Case with a cogging torque and a fault on one phase}

Simulations with a faulty machine are performed to confirm the validity of the proposed method. An additional pulsation of the electromagnetic torque always appears when one of the machine's phases is faulty. The compensation of this pulsation is ensured by the healthy phases. In the following, the third phase of machine is faulty and the results are presented by Fig. 13. In spite of a faulty phase, the control based on the 

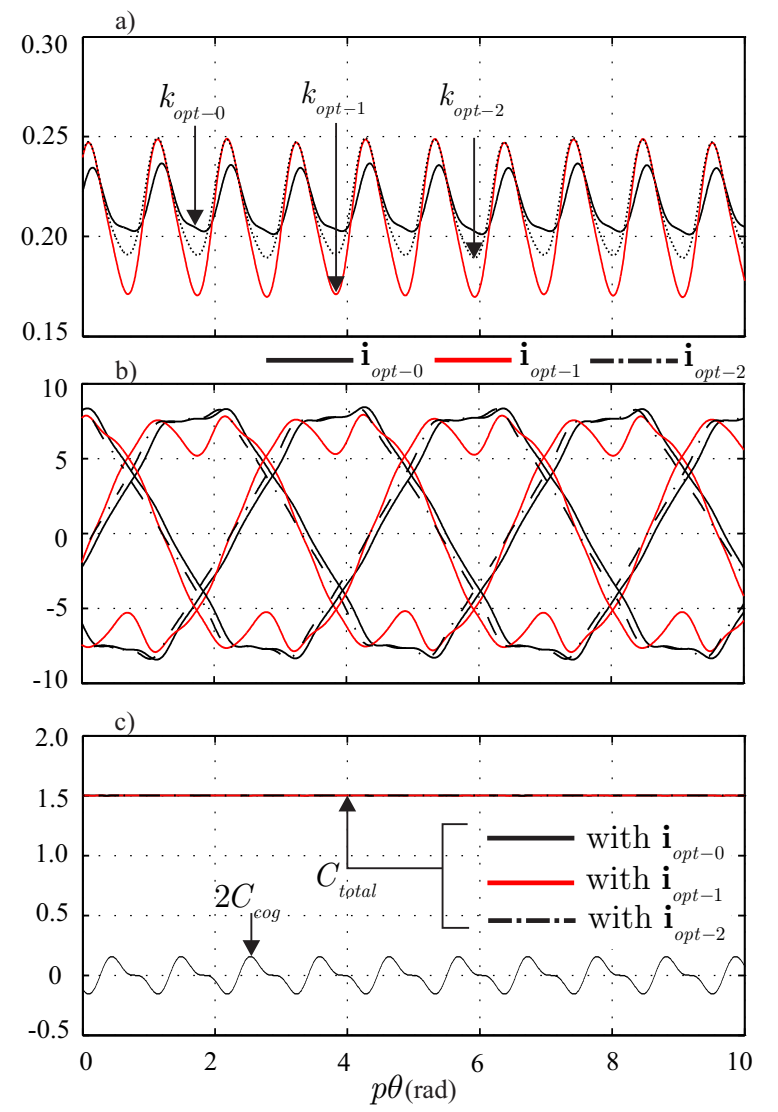

Fig. 12. Control performance with a cogging torque; a) $k_{o p t-0}, k_{o p t-1}$ and $k_{\text {opt }-2}(\mathrm{~A} / \mathrm{Wb})$ obtained by the Adaline controller; b) optimal currents obtained with three approaches (A); c) torque developed (N.m) and cogging torque (N.m)

three strategies is able to maintain the torque as a constant. Comparatively to the results obtained in Fig. 12 (with a cogging torque but no faulty phase), it can be seen that there are more harmonics in the optimal functions $k_{o p t-i}$ in the presence of a fault. According to the training capabilities of the Adaline, these harmonics are adjusted in real time in order to produce the currents that compensate for the torque pulsation created by the faulty phase. Finally, a desired constant torque is obtained.

The proposed neural approaches are also compared to a PI (Proportional Integrator) controller under the same faulty conditions. Fig. $13 \mathrm{c}$ ) shows the irregular behavior of the torque obtained by the PI controller. The neuronal controller based on the optimal strategies is more efficient. Maintaining a constant torque under faulty phase conditions remains a difficult task.

\section{EXPERIMENTAL RESULTS}

A three-phase non-sinusoidal machine PMSM with $R_{s}=3$ $\Omega, L_{s}=12.25 \mathrm{mH}$ and a pair poles number $p=3$ is connected to a three-phase Voltage Source Inverter (VSI). The rotor's position as well as the stator currents are measured in realtime by using an incremental coder and currents sensors. The measures are sent to a process running on a dSPACE DS1104 board hosted by a PC. The process consists of the control
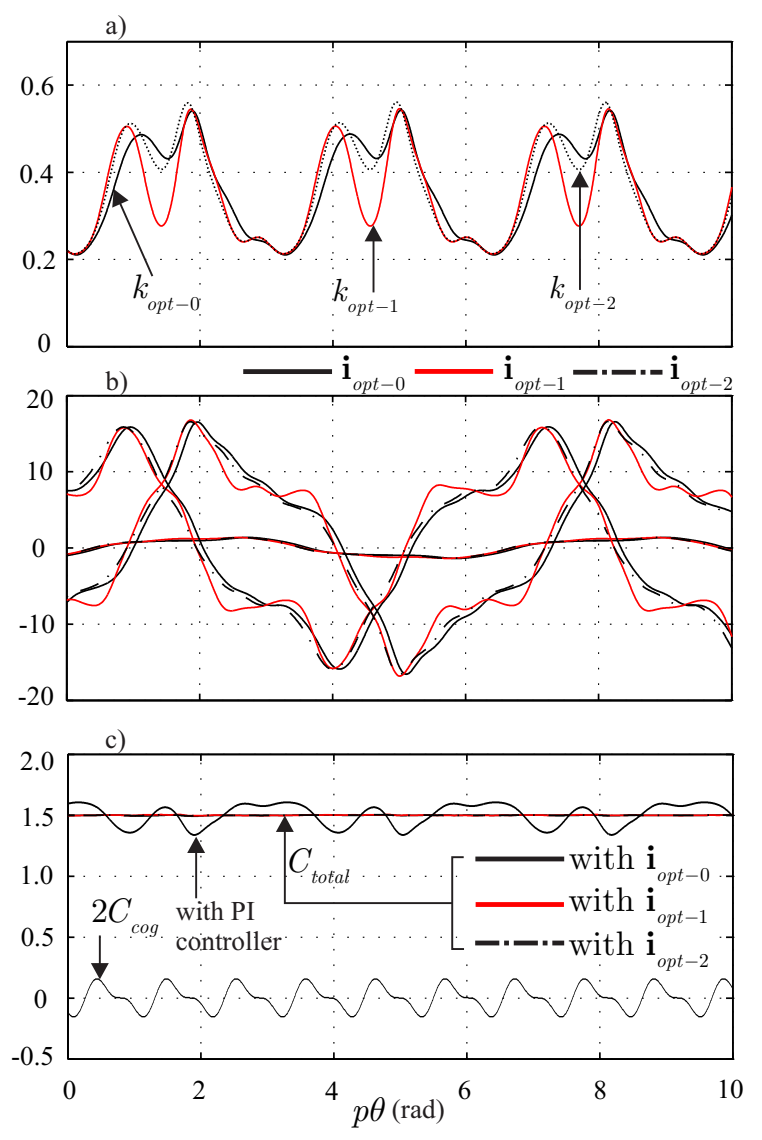

Fig. 13. Control performance with a cogging torque and a fault on one phase; a) $k_{o p t-0}, k_{o p t-1}$ and $k_{o p t-2}(\mathrm{~A} / \mathrm{Wb})$ obtained by the Adaline controller; b) optimal currents obtained with three approaches (A); c) torque developed (N.m) and cogging torque (N.m)

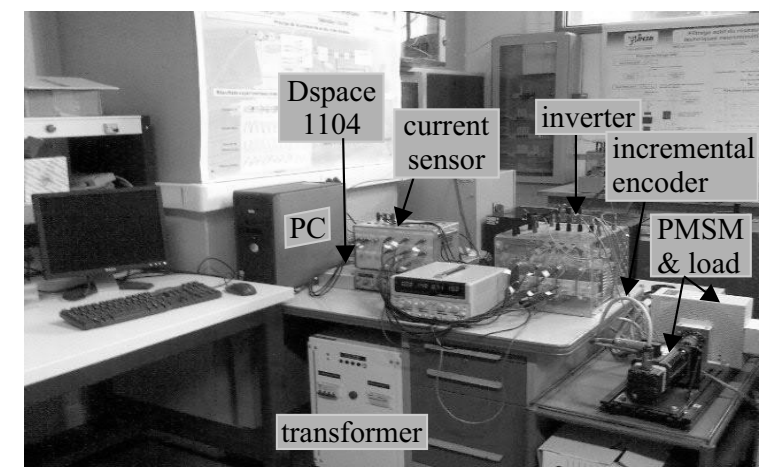

Fig. 14. Experimental platform setup

algorithm based on the proposed strategies which provides the signals sent to a PWM generator for the control the inverter.

\section{A. Speed normalized back-EMF estimation}

In practice, the PMSM is actuated by an induction machine which has no cogging torque in order to precisely estimate the speed normalized back-EMF. In this experiment, the speed and the back-EMF are measured by standard sensors. The speed normalized back-EMF depends on the internal structure (rotor and stator) of the machine and its amplitude is not related to the rotor speed. 


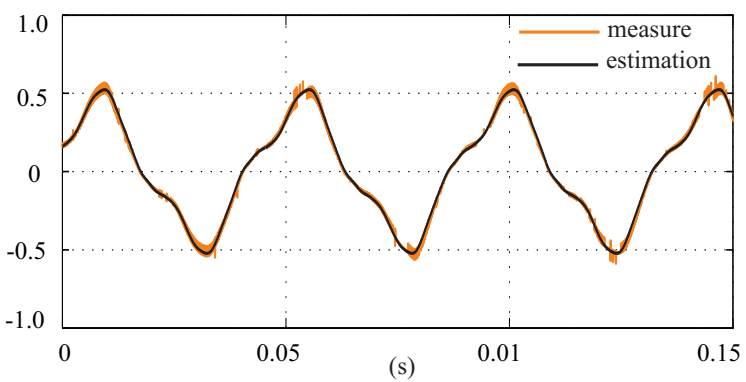

Fig. 15. Estimation of the speed normalized back-EMF by an Adaline (experimentation)

The optimal functions are learned with an Adaline network with an input vector composed of $\cos k p \theta$ and $\sin k p \theta$ terms with $k$ varies from 0 to 15 . After convergence, the signal $k_{1}=$ $\frac{e_{1}}{\Omega}$ is estimated with:

$$
\begin{aligned}
k_{1}= & -0.234 \cos (p \theta)+0.563 \sin (p \theta) \\
& +0.123 \cos (3 p \theta)+0.060 \sin (3 p \theta) \\
& -0.003 \cos (5 p \theta)+0.007 \sin (5 p \theta) \\
& +0.001 \cos (7 p \theta)-0.003 \sin (7 p \theta) \\
& +0.002 \cos (9 p \theta)+0.005 \sin (9 p \theta) \\
& +0.003 \cos (11 p \theta)+0.003 \sin (11 p \theta)+\ldots
\end{aligned}
$$

In (59), terms of ranks 13 and 15 are negligible and are therefore not written down. The simultaneous presence of cosine and sine terms clearly indicates the dissymmetry of the back-EMF. Moreover, there are no even terms in the backEMF, the torque is thus $C_{q n^{\prime}}$ with $n^{\prime}=6$. The estimated speed normalized back-EMF is given by Fig. 15 .

\section{B. Neural speed control}

The torque control scheme can not be carried out because the plate-form must be equipped with a torque meter. Thus, only the speed control scheme is presented.

The test machine is a star coupled PMSM. Therefore, only the strategy with $\mathbf{i}_{o p t-0}$ or with $\mathbf{i}_{o p t-2}$ can be employed. We chose the strategy based on $\mathbf{i}_{\text {opt-2 }}$ because of its lower ohmic losses. In (59), we note: $k_{\max }^{\prime}=11$. By taking the highest angular frequency of $C_{\operatorname{cog}}$ is $m l_{\max }=18$, we chose $N=3$ to compensate all the significant torque harmonics.

A constant reference speed has been fixed at $\Omega_{r e f}=70$ $\mathrm{rad} / \mathrm{s}$. Results are presented by Fig. 16. Fig. 16 a) shows the electromagnetic torque $C_{e m}$. We can notice that the expression (17) is justified. The pulsation of $C_{e m}$ compensates for the cogging torque that exists in the motor. This compensation leads to a smooth speed which is shown in Fig. 16 c). The reference currents obtained by the optimal solution and the measured currents are shown by Fig. 16 b). It can be seen that the resulting currents provided by the neural current controller are close to their references. The non-sinusoidal currents obtained with the Adaline controller compensate for all the torque ripple.

Finally, Fig. 17 compares the speed obtained by our approach to the one obtained when the motor is feed by the sinusoidal currents. It clearly shows that the speed pulsation
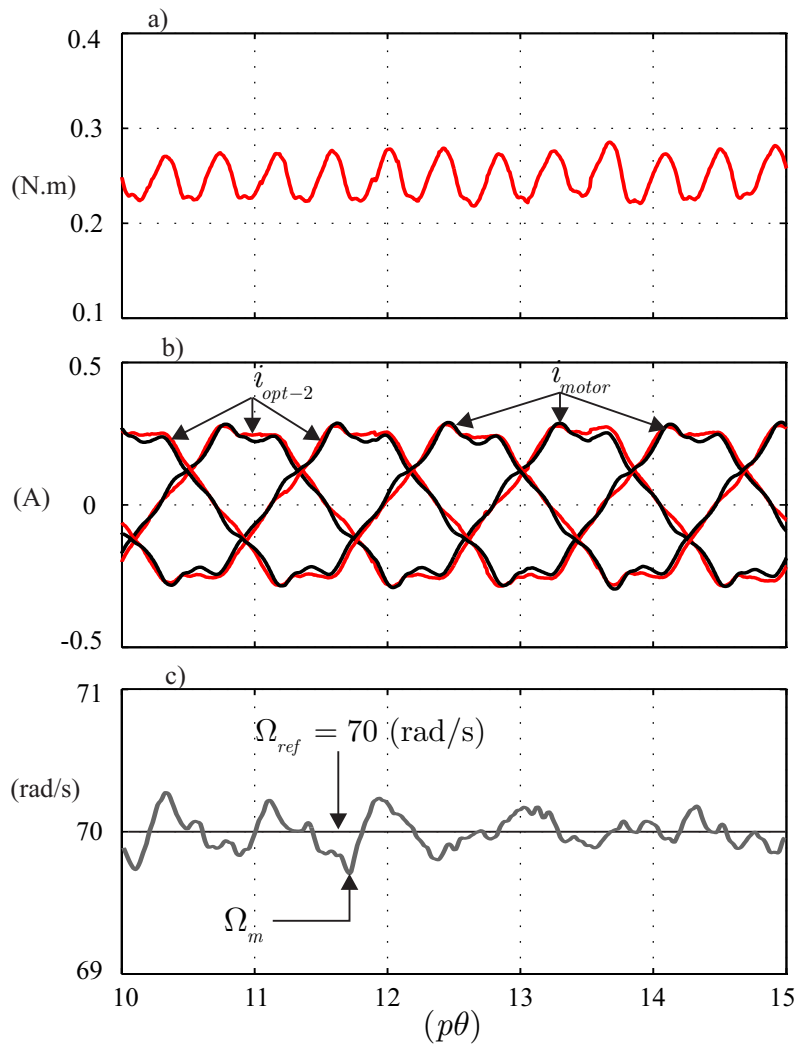

Fig. 16. Experimental performance of the PMSM speed control: a) electromagnetic torque, b) $\mathbf{i}_{\text {opt }-2}$ obtained and currents consumed by PMSM $\left.i_{\text {motor }}, \mathrm{c}\right)$ rotor speed obtained

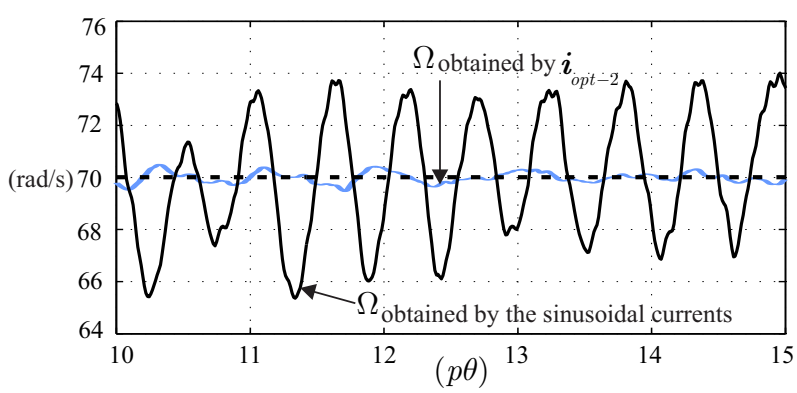

Fig. 17. Experimental speed obtained by the currents $\mathbf{i}_{o p t-2}$ compared to the one derived by the sinusoidal currents

obtained by the neural approach is eliminated. When the machine is supplied by the sinusoidal currents, it is obvious that there is a torque ripple which leads to the speed pulsation. By using the proposed approach, the problem of torque and speed pulsation that is present in the control of conventional PMSMs have been solved.

\section{CONCLUSION}

A new solution to calculate the optimal currents for nonsinusoidal multiphase PMSMs and particularly for three-phase non-sinusoidal machines has been presented in this paper. These optimal currents are derived from control strategies which depend on machine's structure (for example, with or without the neutral current). The optimization criterion consists of a desired constant torque and minimal ohmic losses. 
These optimal currents are directly deduced from a geometrical development instead of calculations based on the Lagrange optimization. A new torque (or speed) control scheme has been proposed. According to the learning capability of Adaline neural network, the optimal currents are obtained in real time. In each control scheme, the Adaline controller takes the place of the traditional torque or speed controller for ensuring the convergence of the motor's torque or speed toward the desired one. The torque (or speed) ripple is efficiently compensated. This has been verified by various tests and comparisons under different conditions, even when one of the machine's phases is faulty. The proposed simulations and experiments clearly confirm the high performances of our approaches.

\section{REFERENCES}

[1] T. M. Jahns and W. L. Soong, "Pulsating torque minimization techniques of permanent magnet ac motor drives - a review," IEEE Trans. on Industrial Electronics, vol. 43, no. 2, pp. 321-330, 1996.

[2] H. R. Bolton and R. A. Ashen, "Influence of motor design and feed-current waveform on torque ripple in brushless dc drives," IEE Proceedings on Electric Power Applications, vol. 131, no. 3, 1984.

[3] S. Chen, C. Namuduri, and S. Mir, "Controller-induced parasitic torque ripples in a pm synchronous motor," IEEE Trans. on Industry Applications, vol. 38, no. 5, pp. 1273-1281, 2002.

[4] W. Qian, S. Panda, and J.-X. Xu, "Torque ripple minimization in pm synchronous motors using iterative learning control," IEEE Trans. on Power Electronics, vol. 19, no. 2, pp. 272-279, 2004.

[5] M. Islam, S. Mir, and T. Sebastian, "Issues in reducing the cogging torque of mass-produced permanent-magnet brushless dc motor," IEEE Trans. on Industrial Applications, vol. 40, no. 3, pp. 813-820, 2004.

[6] G. Sturzer, D. Flieller, and J.-P. Louis, "Extension of the park's transformation applied to non-sinusoidal saturated synchronous motors," European Power Electronics and Drives, vol. 12, no. 3, pp. 16-20, 2002.

[7] _ - "Mathematical and experimental method to obtain the inverse modelling of nonsinusoidal and saturated synchronous reluctance motors," IEEE Trans. on Energy Conversion, vol. 18, no. 4, pp. 494-500, 2003.

[8] N. J. Nagel and R. D. Lorenz, "Rotating vector methods for smooth torque control of a switched reluctance motor drive," IEEE Trans. on Industry Applications, vol. 36, no. 2, pp. 540-548, 2000.

[9] Y. Zhang, J. Zhu, W. Xu, and Y. Guo, "A simple method to reduce torque ripple in direct torque-controlled permanent-magnet synchronous motor by using vectors with variable amplitude and angle," IEEE Trans. on Industrial Electronics, vol. 58, no. 7, pp. 2848-2859, 2011.

[10] H. Zhu, X. Xi, and $\mathrm{Y}$. Li, "Torque ripple reduction of the torque predictive control scheme for permanent-magnet synchronous motors," IEEE Trans. on Industrial Electronics, vol. 59, no. 2, pp. 871-877, 2012

[11] S. Jian and L. Tie-Cai, "New method to eliminate commutation torque ripple of brushless dc motor with minimum commutation time," IEEE Trans. on Industrial Electronics, vol. 60, no. 6, pp. 2139-2146, 2013.

[12] D. Wang, X. Wang, Y. Yang, and R. Zhang, "Optimization of magnetic pole shifting to reduce cogging torque in solid-rotor permanent-magnet synchronous motors," IEEE Trans. on Magnetics, vol. 46, no. 5, pp. 1228-1234, 2010.

[13] R. Islam, I. Husain, A. Fardoun, and K. McLaughlin, "Permanentmagnet synchronous motor magnet designs with skewing for torque ripple and cogging torque reduction," IEEE Trans. on Industry Applications, vol. 45, no. 1, pp. 152-160, 2009.

[14] U.-J. Seo, Y.-D. Chun, J.-H. Choi, P.-W. Han, D.-H. Koo, and J. Lee, "A technique of torque ripple reduction in interior permanent magnet synchronous motor," IEEE Trans. on Magnetics, vol. 47, no. 10, pp. 3240-3243, 2011.

[15] L. J. Wu, Z. Q. Zhu, D. A. Staton, M. Popescu, and D. Hawkins, "Comparison of analytical models of cogging torque in surface-mounted pm machines," IEEE Trans. on Industrial Electronics, vol. 59, no. 6, pp. 2414-2425, 2012.

[16] H. Le-Huy, R. Perret, and R. Feuillet, "Minimization of torque ripple in brushless dc motor drives," IEEE Trans. on Industry Applications, vol. IA-22, no. 4, pp. 748-755, 1986.

[17] J. Y. Hung and Z. Ding, "Minimization of torque ripple in permanent magnet motors: a closed form solution," Int. Conf. on Ind. Electronics, Control, Instrumentation and Automation, vol. 1, pp. 459-463, 1992.
[18] — , "Design of currents to reduce torque ripple in brushless permanent magnet motors," IEE Proceedings on Electric Power Applications. Part $B$, vol. 140, no. 4, pp. 260-266, 1993.

[19] S. Clenet, Y. Lefèvre, N. Sadowski, S. Astier, and M. Lajoie-Mazenc, "Compensation of permanent magnet motors torque ripple by means of current supply waveshapes control determined by finite element method," IEEE Trans. on Magnetics, vol. 29, no. 2, pp. 2019-2023, 1993.

[20] H. Kogure, K. Shinohara, and A. Nonaka, "Magnet configurations and current control for high torque to current ratio in interim permanent magnet synchronous motors," in IEEE International Electric Machines and Drives Conference, vol. 1, 2003, pp. 353-359.

[21] A. P. Wu and P. L. Chapman, "Simple expressions for optimal current waveforms for permanent-magnet synchronous machine drives," IEEE Trans. on Power Electronics, vol. 20, no. 1, pp. 151-157, 2005.

[22] P. L. Chapman, S. D. Sudhoff, and C. A. Whitcomb, "Optimal current control strategies for surface-mounted permanent-magnet synchronous machine drives," IEEE Trans. on Energy Conversion, vol. 14, no. 4, 1999.

[23] K. Y. Cho, J. D. Bae, S. K. Chung, and M. J. Youn, "Torque harmonics minimisation in permanent magnet synchronous motor with back emf estimation," IEE Proceedings on Electric Power Applications, vol. 141, no. 6, pp. 323-330, 1994.

[24] D. Grenier, L. A. Dessaint, O. Akhrif, and J.-P. Louis, "A park-like transformation for the study and the control of a nonsinusoidal brushless dc motor," in Proceedings of IECON 21st International Conference on Industrial Electronics, Control, and Instrumentation, vol. 2, 1995, pp. 836-843.

[25] D. Grenier, L. A. Dessaint, O. Akhrif, Y. Bonnassieux, and B. Le Pioufle, "Experimental nonlinear torque control of a permanent-magnet synchronous motor using saliency," IEEE Trans. on Industrial Electronics, vol. 44, no. 5, pp. 680-687, 1997.

[26] N. Matsui, "Autonomous torque ripple compensation of dd motor by torque observer," in Asia-Pacific Workshop on Advances in Motion Control, 1993, pp. 19-24

[27] P. Mattavelli, L. Tubiana, and M. Zigliotto, "Torque-ripple reduction in pm synchronous motor drives using repetitive current control," IEEE Trans. on Power Electronics, vol. 20, no. 6, pp. 1423-1431, 2005.

[28] X. Kestelyn and E. Semail, "A vectorial approach for generation of optimal current references for multiphase permanent-magnet synchronous machines in real time," IEEE Trans. on Industrial Electronics, vol. 58 , no. 11, pp. 5057-5065, 2011.

[29] W. Zhao, M. Cheng, K. T. Chau, R. Cao, and J. Ji, "Remedial injectedharmonic-current operation of redundant flux-switching permanentmagnet motor drives," IEEE Trans. on Industrial Electronics, vol. 60, no. 1, pp. 151-159, 2013.

[30] D. Ould Abdeslam, P. Wira, J. Mercklé, D. Flieller, and Y. A. Chapuis, "A unified artificial neural network architecture for active power filters," IEEE Trans. on Industrial Electronics, vol. 54, no. 1, pp. 61-76, 2007.

[31] N. K. Nguyen, P. Wira, D. Flieller, D. Ould Abdeslam, and J. Mercklé, "A comparative experimental study of neural and conventional controllers for an active power filter," in 36th Annual Conference of the IEEE Industrial Electronics Society (IECON'10), Glendale, Arizona, USA, 2010, pp. 1995-2000.

[32] Z. Zhu and D. Howe, "Influence of design parameters on cogging torque in permanent magnet machines," IEEE Trans. on Energy Conversion, vol. 15 , no. 4, pp. 407-412, 2000.

[33] E. Favre, L. Cardoletti, and M. Jufer, "Permanent-magnet synchronous motors: A comprehensive approach to cogging torque suppression," IEEE Trans. on Industry Applications, vol. 29, no. 6, pp. 1141-1149, 1993.

[34] L. Dosiek and P. Pillay, "Cogging torque reduction in permanent magnet machines," IEEE Trans. on Industry Applications, vol. 43, no. 6, pp. $1565-1571,2007$.

[35] D. C. Hanselman, "Minimum torque ripple, maximum efficiency excitation of brushless permanent magnet motors," IEEE Trans. on Industrial Electronics, vol. 41, no. 3, pp. 292-300, 1994.

[36] J. Y. Hung, "Design of the most efficient excitation for a class of electric motor," IEEE Trans. on Circuits and Systems I: Fundamental Theory and Applications, vol. 41, no. 4, pp. 341-344, 1994.

[37] S. Dwari and L. Parsa, "An optimal control technique for multiphase $\mathrm{pm}$ machines under open-circuit faults," IEEE Trans. on Industrial Electronics, vol. 55, no. 5, pp. 1988-1995, 2008.

[38] B. Widrow and E. Walach, Adaptive Inverse Control. Prentice-Hall, Inc., 1996. 


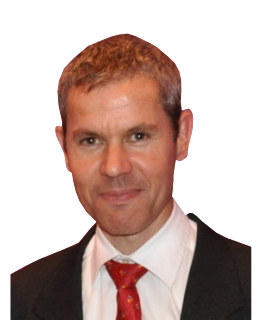

Damien Flieller received the M.Sc. degree in Electrical Engineering from the Ecole Normale Supérieure (Cachan), France, in 1988 and the Ph.D. degree in Electrical Engineering from the University of Paris, France, in 1995. Since 1995, he is an Associate Professor in the Department of Electrical Engineering, INSA of Strasbourg, France. He is now director of the ERGE Group (Electrical Engineering Research Team). His research's field are modeling and control of synchronous motors, active filter, and induction heating converters.

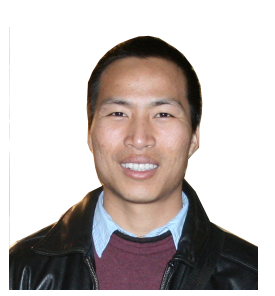

Ngac Ky Nguyen received his B.Sc degree in Electrical Engineering from the Ho Chi Minh City University of Technology (HCMUT), Viet Nam in 2005. In France, he received his M.Sc. from Poly'Tech Nantes, in 2007 and his Ph.D. from the University of Haute Alsace (UHA), in 2010, both in Electrical and Electronic Engineering. From 2011 to 2012, he was with the Electrical Engineering Department, INSA of Strasbourg, France. Since September 2012, he is Associate Professor with the Laboratoire d'Electrotechnique et d'Electronique de Puissance de Lille (L2EP), Arts et Métiers ParisTech, Lille Cedex, France. His research interests are modeling and control of synchronous motors and power converters.

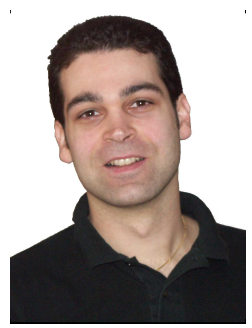

Patrice Wira (M'04) received the M.Sc. degree and the Ph.D. degree in Electrical Engineering from the University of Haute Alsace, Mulhouse, France, in 1997 and 2002, respectively. He received the Accreditation to Supervise Research (the French Habilitation à Diriger des Recherches) in Computer Sciences from the University of Haute Alsace in 2009. He was an Associate Professor with the MIPS Laboratory (Laboratoire Modélisation, Intelligence, Processus, Système) at the University of Haute Alsace. Since 2011, he is a Full Professor. He is author or coauthor of more than 20 technical papers covering his research interests from artificial neural networks for the modeling and simulation of complex automation systems, neuro-control approaches, to adaptive control systems.

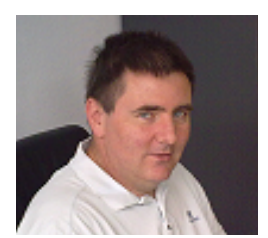

Guy Sturtzer received the Ph.D. degree in Electrical Engineering from the Ecole Normale Supérieure, Cachan, France, in 2001. He joined the Department of Electrical Engineering, INSA de Strasbourg, France, where he is an Associate Professor. His main interests include electrical machines, power converters and renewable energies.

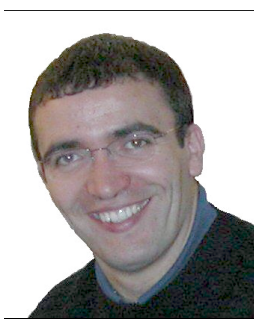

Djaffar Ould Abdeslam received the Ing. degree in Electronics Engineering from the University of TiziOuzou, Algeria, in 2000, M.Sc. degree in Electrical Engineering from the University of Franche-Comté, Besançon, France, in 2002 and the Ph.D. degree in ele ctrical engineering from the University of Haute Alsace (UHA), Mulhouse, France, in 2005. Since 2005, he is with the MIPS Laboratory, UHA, as an Associate Professor. His work concerns artificial neural networks, fuzzy logic and advanced control applied to power active filters and power electronics.

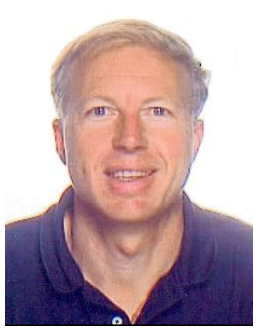

Jean Mercklé received the M.Sc. and Ph.D.degrees in Electrical from University Nancy I, Nancy, France, in 1982 and 1988, respectively. In 1988, he joined the MIPS Laboratory, University of Haute Alsace, Mulhouse, France, where he participated in several adaptive signal processing projects. From 1991 to 1993, he was with the department of Electrical and Computer Engineering, University of California and San Diego, contributing to a 3D optoelectronic neural architecture with efficient learning. He is currently a professor of Electrical and Computer Engineering. His research interests include adaptive neural computation with application to power electronic systems control. 